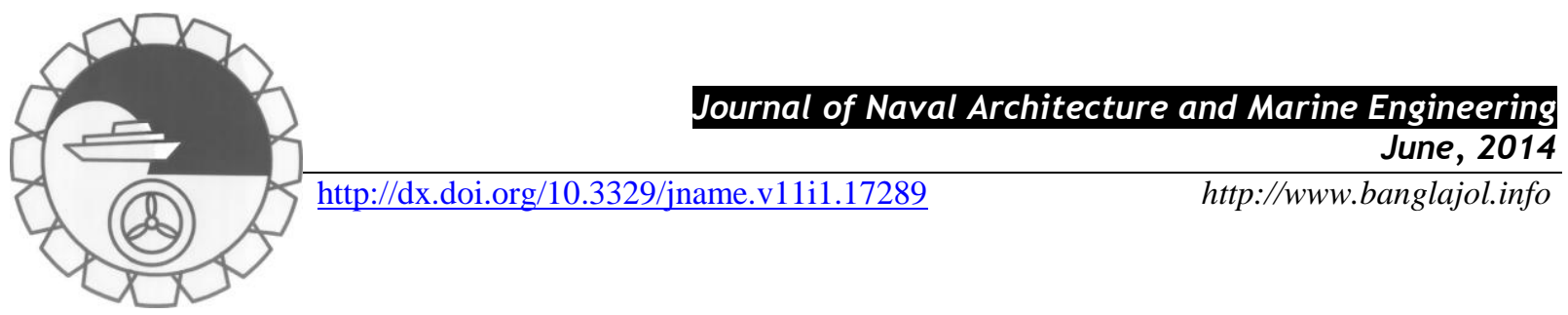

\title{
PREDICTION OF THE DYNAMIC RESPONSES FOR TWO CONTAINERSHIPS OPERATING IN THE BLACK SEA
}

\author{
Carmen Gasparotti ${ }^{1}$ and Liliana Rusu ${ }^{2}$
}

${ }^{1}$ Department of Naval Architecture, Dunarea de Jos University of Galati, Romania, Email: carmen.gasparotti@ugal.ro

${ }^{2}$ Department of Mechanical Engineering, Dunarea de Jos University of Galati, Romania, Email: liliana.rusu@ugal.ro

\begin{abstract}
:
This work presents a methodology for the evaluation of the vessels operability in the basin of the Black Sea. The approach proposed is based on the results provided by a wave prediction system that was implemented and validated in the Black Sea. This offers a meaningful framework in the assessment of the seakeeping performance for ships operating in different conditions. The aim of the work is to improve the seakeeping performances for various types of ships that sail in the Romanian coastal zones. Two containerships are considered, of 1300TEU and 800TEU respectively, which have however the same displacement. For predicting the ship motions induced by the various wave conditions encountered in the operational area, it is necessary to know the transfer functions for different ship speeds and heading angles. These are computed with a numerical code based on the strip theory. The predicted motions are then compared with the limit values of the relevant seakeeping criteria, considered as the criteria for checking the operability of the ship. By defining the acceptable operating boundaries, the ship behavior in waves can be quantified. The vessel meets the criteria for those combinations wave height-wave period that are below the limit curves. The results are presented as operational maps for the Black Sea basin, allowing the identification of the areas that should be avoided due to unfavorable weather conditions. The methodology proposed herewith can be extended and applied to various marine environments and types of ships.
\end{abstract}

Keywords: Numerical wave models, seakeeping performance, containerships operability, seakeeping criteria, ship responses

\section{NOMENCLATURE}

F amplitude of the random process

$g \quad$ gravitational acceleration

$H_{s} \quad$ significant wave height

$H_{\text {slimit }} \quad$ limiting significant wave height

$H_{y}\left(\omega_{e}\right) \quad$ transfer function

$H_{s}^{b r} \quad$ breaking wave height

$H_{R 4} \quad$ transfer functions for roll

$H_{T 5} \quad$ transfer functions for pitch

$H_{Z} \quad$ transfer functions for heave

$N_{c} \quad$ number of the successive cycles

$T_{p} \quad$ peak wave period

$T_{z} \quad$ mean wave period

$P_{s} \quad$ probability of the random process

$p_{C R}$
$H_{\text {smax }} \quad$ maximum significant wave height

$\begin{array}{ll}R_{S} & \text { significant value of the response } \\ R_{\max } & \text { limiting magnitude of the response } \\ R I & \text { risk index } \\ R I_{c} & \text { risk index for a specific criterion } \\ V & \text { ship speed } \\ \text { Greek Symbols } \\ \beta & \text { heading angle } \\ \sigma_{R} & \text { root mean square of the response } \\ \sigma_{R}^{2} & \text { variance of the process } \\ \sigma_{C R} & \text { limiting root mean square of the response } \\ \Phi_{y y}\left(\omega_{e}\right) & \text { response spectrum } \\ \Phi_{\zeta v \zeta v}\left(\omega_{e}\right) & \text { wave spectrum } \\ \omega_{0} & \text { wave frequency } \\ \omega_{e} & \text { encounter frequency }\end{array}$

\section{Introduction}

The maritime transportation is a complex activity both due to the volume and the nature of goods involved in traffic, but also due to the specific operating conditions that require special measures for the safety of the ships. In the maritime transportation an interaction between technology, environment and organizational factors is 
encountered, each of these factors playing a significant role in the safety of the ship at sea (Hanzu-Pazara, 2007).

It is widely recognized that accidents at sea are sometimes hard to be avoided. After analysing the causes of a wide range of maritime accidents, as well as of their effects, international organizations like UN, CE and specialized agencies such as IMO (International Maritime Organization) and ILO (International Labour Organization) have developed a number of conventions, regulations, rules, norms and international standards containing essential criteria concerning the safety (as for example IMO, 1994). Despite the measures taken at international level to improve the safety at sea, the marine accidents in recent years prove that they still remain a constant threat (Gasparotti, 2010). There is however a set of causes that may lead usually to an accident. Thus, the main factors that generate accidents are: high density traffic, unfavourable hydro meteorological conditions (storms, high waves, rain and frost), navigating obstacles, sea conditions (sea depth and seabed topography), reduced visibility, human errors and latent defects of the ships. These can individually, or in combination, have as a result the development of marine accidents (Milan and Gomoiu, 2008; Wayment and Wagstaff, 1999; Zang et al., 2006).

In the Black Sea, most of the accidents occurred during the cold season, when usually unfavorable hydrometeorological conditions are encountered. In winter, in the western and north-western parts of the Black Sea, circumstances of producing storms are continuously created, because of the aero-synoptic specific conditions. A Bayesian Belief Network (BBN) have been used in the maritime industry with the development of some specific models to assess and identify the risk factors associated to a given context (Eleye-Datubo et al., 2006; Trucco et al., 2006; Norrington et al., 2008). Such a BBN model for maritime accidents was also developed by Antão et al. (2008) with the inclusion of the wave data (significant wave heights), in order to assess the correlation between their amplitude and certain accident typologies and related consequences (human injuries or fatalities). The study has shown that the type and the probability of producing an accident depend directly on the type of the ship. Thus, at small significant wave heights $(0-2 \mathrm{~m})$, the occurrence probability of an accident in the case of the commercial vessels is also small, but this probability increases in the case of the fishing vessels operating near the coastal areas, especially in wave breaking areas. In the case of large significant wave heights (4-6m), the probability of accidents highly increases, in a range between 3-13 times.

Some recent studies (Guedes Soares et al., 2001; Bitner-Gregersen and Guedes Soares, 2007) have shown that most of the marine accidents induced due to severe weather conditions occurred in areas with the highest significant wave height or with wave steepness greater than average. The general statistics show that about $23 \%$ of the ships accidents are caused by the sea state and weather conditions, the latter being in fact the second most common cause for such events (Toffoli et al., 2003). Toffoli et al. (2003) also showed that the responses of the vessels at a certain sea state depend on the type and the size of vessel. It was noticed that the ships are vulnerable mainly to the wave lengths greater than half of the ship length and only few accidents occurred at wave lengths less than half of the ship length.

On the other hand, different types of ships seem to have different causes of accidents. As regards the containerships, they can capsize in the case of high roll motion, usually for beam sea conditions or in very extreme oblique waves, case characterized by high amplitudes on heave, pitch and roll motions. A recent example in this direction is represented by the accident produced in 14 February 2014. After the containership Svendborg Maersk left the Bay of Biscay it was struck by heavy seas off the coast of France. The owner company told that the extreme weather had an unexpectedly forceful impact on the ship's movements. After the ship arrived in the Spanish port of Malaga for repairs, it was discovered that about 520 containers were unaccounted for. Another example is the accident of the container vessel MOL Comfort. This experienced a crack amidships and ingresses water in the hold while sailing from Singapore to Jeddah on the Indian Ocean on $17^{\text {th }}$ of June, 2013 due to inclement weather conditions.

Nowadays, the numerical wave models have shown very good capability to predict the wave conditions generated by the wind fields over the sea (Rusu et al., 2005; Rusu 2010a; Rusu, 2011; Rusu and Guedes Soares, 2013). In the present work the seakeeping qualities of two ships will be quantified by evaluating the corresponding the operability indexes, using the predictions provided by a numerical wave model. A wave modelling system, SWAN based (Simulating Waves Nearshore, Booij et al., 1999) was implemented and validated at the level of the entire basin of the Black Sea (Rusu, 2010b; Rusu and Ivan, 2010) in order to be able to provide reliable nowcast and forecast products for the wave conditions. 
The seakeeping performances of two containerships operating in the Black Sea basin are investigated in the present work. These evaluations of the dynamic responses under predicted sea states are based on the results of the numerical wave modelling system and on the ship transfer functions.

\section{Procedure for Assessment of The Sea-keeping Performance}

The procedure considered for assessment of the seakeeping performance of a ship is based on the analysis of the ship dynamic response in irregular waves, corresponding to the sea states. The procedure starts with the prediction of the ship's hydrodynamic response for a range of speed and heading angle values. The amplitude of the ship motions in irregular waves are short term predicted according to the sea state and the specific wave spectra. Finally, based on the ship's operability limits established by the limiting response criteria, the seakeeping operability indexes are obtained (Sariöz and Narli, 2005).

The evaluation of the seakeeping performance of a ship largely depends on the environmental conditions as well as on the defined criteria, and this is the main reason for that any comparison related to problem as: the ship speeds, the influence of the heading angles, the loading conditions, etc., represents a complex problem (ITTC, 1999). In irregular waves, short and long term distributions can be used to estimate the most probable maximum values of the responses. The first step includes the computation of the ship response transfer functions corresponding to the ship main degrees of freedom. The transfer functions include the absolute ship motions (heave, roll and pitch), and the derived responses at selected positions on the ship, such as relative motions and accelerations. For this, a program code developed by Domnisoru (2001) and Domnisoru el al. (2009) based on the strip theory (Salvesen et al., 1970; Bertram et al., 2006) was used Then, it is necessary to compute the ship responses to the complete range of the short-term sea states. Finally, combining the transfer functions with the specified wave spectra, the response spectra are obtained.

\subsection{Ship responses to irregular waves}

The establishment of the seakeeping performance of a ship and the determination of the explicit design parameters have to be done in a realistic seaway. The response spectrum $\Phi_{y y}\left(\omega_{e}\right)$ is obtained from the input wave spectrum $\Phi_{\zeta \zeta \zeta v}\left(\omega_{e}\right)$ by means of the response transfer function $H_{y}\left(\omega_{e}\right)$ :

$$
\phi_{y y}\left(\omega_{e}\right)=\left|H_{y}\left(\omega_{e}\right)\right|^{2} \cdot \phi_{\zeta v \zeta v}\left(\omega_{e}\right)
$$

It is known that, the wave spectra which a ship encounters vary continuously in space and time. Since the sea states were assumed as stationary, zero mean Gaussian processes, and because the response is linear, it can be considered that the same model describes de response process. This implies that the statistical properties of the responses may be derived from the moments of the response spectra.

The variance of the process can be obtained by integrating the spectrum:

$$
\sigma_{R}^{2}=\int_{0}^{\infty} \phi_{y y}\left(\omega_{e}\right) d \omega_{e}=\int_{0}^{\infty}\left|H_{y}\left(\omega_{e}\right)\right|^{2} \phi_{\zeta v \zeta v}\left(\omega_{e}\right) d \omega_{e} .
$$

The significant value of the response $R_{S}$ (double amplitude), can be computed from the standard deviation as

$$
R_{S}=4 \sigma_{R} \text {. }
$$

The seakeeping criteria estimations are based on well-known equations applicable to random processes whose amplitudes can be approximately assumed as distributed following a Rayleigh law, according to which the probability $P_{s}$ for that the amplitude of the random process exceeds a certain level $\mathrm{F}$ is computed with the formula:

$$
P_{S}(F)=\exp \left(-\frac{F^{2}}{2 \sigma_{R}^{2}}\right)
$$

where $\sigma_{R}^{2}$ is the variance of the process. The most probable maximum value in $N_{c}$ successive cycles is obtained from relationship bellow:

$$
F_{\max }=\sqrt{2 \sigma_{R}^{2} \ln N_{c}} .
$$

In irregular waves, short and long term distributions can be used to estimate the most probable maximum values of the responses. Nevertheless, only these results alone are not a good measure of the seakeeping quality of a ship. For this reason, the seakeeping quality will be quantified by an operability index. The relationship between the ship operability and the mission characteristics is established through the seakeeping criteria. In this way, the 
seakeeping index will indicate if the ship responses are bellow or over to those defined by the criteria (Fonseca and Guedes Soares, 2002).

\subsection{Seakeeping criteria}

An important part in the assessment of the seakeeping effect on the vessel's efficiency is the evaluation of the critical levels corresponding to relevant seakeeping criteria. When these are exceeded the crew's abilities to safely and efficiently perform their duties are degraded (Platonov and Trub, 2010). Since the seakeeping criteria are defined also in terms of the accelerations felt on-board and of the relative motions between the hull and the waves, these quantities are computed for all the relevant points on the ship, combining the absolute motions and the wave motions.

Usually the seakeeping criteria related to the absolute motions and accelerations are presented in terms of a limit value of the root mean square $\left(\sigma_{R}\right.$ ) of the response. The criteria can be also defined in terms of the probability of exceeding a critical value, as it is used for slamming, deck wetness, or propeller emergence. The criteria are defined either in terms of the root mean square of the response ( $r m s)$ or in terms of permitted probability of occurrence (prob). If the seakeeping criterion is defined as a limiting root mean square of the response $\sigma_{C R}$, then the maximum significant wave height for a given mean wave period $T_{z}$ and ship heading is computed as:

$$
H_{s \max }\left(T_{Z}, \beta\right)=\frac{\sigma_{C R}}{\sigma_{R 1}} .
$$

If the criterion is defined as a probability of exceeding a critical value $p_{C R}$, then the corresponding root mean square of the response is obtained from the following relationship:

$$
\sigma_{C R}=\sqrt{\frac{R_{\max }^{2}}{2 \ln \left(1 / p_{C R}\right)}},
$$

where $R_{\max }$ is the limiting magnitude of the response which has the probability $\sigma_{C R}$ of being exceeded. As an example, for the green water on the deck phenomena $R_{\max }$ is usually the free board at the bow. Knowing now the probability distribution of the short-term sea states for a given area, it is possible to select all the sea states where the vessel is operational.

Several seakeeping criteria related to: the absolute motions, the relative motions, the accelerations, slamming, green water on deck, etc., have been used and are available in the literature. These criteria have been obtained mostly from the experience onboard ships. For this reason, there is a large uncertainty in the definition of the seakeeping criteria. This uncertainty motivated the present analysis related to the influence of varying different seakeeping criteria on the operability index.

The seakeeping criteria can vary vastly from ship to ship and the values chosen play an important role to delimitate the vessel situation, which can be: operable or inoperable due to exceeding of the limiting criterion values. In this study, the values considered for each criterion are presented in Table 1 (where $g$ is the gravity acceleration). It is assumed that green water on deck occurs when the relative motion is larger than the freeboard on the bow, a slam occurs when the relative motion is larger than the draft at the bow and a propeller emergence occurs when 1/4 of the propeller diameter comes out of the water (Fonseca and Guedes Soares, 2002). The seakeeping criteria defined as a limiting root mean square of the response are: roll, pitch, vertical acceleration at the bridge $(\mathrm{VAB})$, lateral acceleration at the bridge $(\mathrm{LAB})$ and vertical acceleration at the forward perpendicular (VAFP). The criteria defined as a probability of exceeding a critical value are slamming (slam), green water on deck $(\mathrm{GW})$ and propeller emergence (PE).

\subsection{Operability indexes}

An effective methodology that links a spectral phase averaged wave model with a model for ship dynamics analysis is presented in this work. The main idea is to use in a certain area the predicted sea states provided by a wave model to compute the seakeeping performances of a ship under operational conditions. The information regarding the ship operability is presented in a simple and straightforward way, by designing maps that provide the risk indexes $(R I)$, which indicate in fact if the operability limits are exceeded at least by one criterion. 
For each speed and heading, the computation of these indexes is based on the relationship that exists between the predicted significant wave height $\left(H_{s}\right)$ in a grid point of the wave computational domain and $H_{\text {slimit }}$ (the lowest values of $H_{s \max }$ ) that corresponds to the mean period $\left(T_{z}\right)$ simulated in that point. In order to obtain immediately the information concerning the relationship that exists between $H_{s}$ and $H_{\text {slimit }}$ in each grid point, $H_{s}$ was divided by the $H_{\text {slimit }}$ value that corresponds to the period $T_{z}$ simulated in that point. In this way, a risk index denoted as $R I$ was defined as:

$$
R I(i, j)=H_{s}(i, j) / H_{\text {slimit }}(i, j),
$$

where $i$ and $j$ represent the indices of the grid points in the computational domain. For the case when $R I<1$, the vessel can navigate without any operational risk relatively to all criteria considered, for a specific heading and speed.

The maps of the operability risk indexes can be also evaluated for a specific criterion, and in this case the indexes $\left(R I_{c}\right)$ are computed with the following relationship:

$$
R I_{c}(i, j)=H_{s}(i, j) / H_{s c \max }(i, j)
$$

where $c$ is related to the limiting criteria considered. In the present study eight criteria were considered, as presented in Table 1.

Table 1: Seakeeping performance criteria for the containerships

\begin{tabular}{|c|c|c|c|}
\hline \multirow{2}{*}{ Response } & \multicolumn{2}{|c|}{$\begin{array}{c}\text { Location of the points analysed for derivate } \\
\text { responses }(\mathrm{m}) \mathrm{x}, \mathrm{y}, \mathrm{z}\end{array}$} & \multirow{2}{*}{ Criterion } \\
\cline { 2 - 3 } & $\mathrm{C} 1$ & $\mathrm{C} 2$ & $6^{\mathbf{o}}(\mathrm{rms})$ \\
\hline Roll & - & - & $3^{\circ}(\mathrm{rms})$ \\
\hline Pitch & - & $75.68,0,6,21$ & $5 \%(\mathrm{prob})$ \\
\hline Green water on deck (GW) & $67.53,0,5.1$ & $61.15,0,-7.29$ & $3 \%$ (prob) \\
\hline Slamming & $54.53,0,-7.3$ & $-63.64,0,-4.8$ & $12 \%(\mathrm{prob})$ \\
\hline Propell. Emergence (PE) & $-57.5,0,-4.7$ & $-55.0,0,15.0$ & $0.15 g(\mathrm{rms})$ \\
\hline Vert. acc. at bridge (VAB) & $-55.2,0,14.45$ & $-55.0,0,15.0$ & $0.15 g(\mathrm{rms})$ \\
\hline Lat. acc. at Bridge (LAB) & $-55.2,0,14.45$ & $75.68,0,0$ & $0.2 \mathrm{~g}(\mathrm{rms})$ \\
\hline Vert. acc. at fwd. pp. (VAFP) & $67.53,0,0$ & \\
\hline
\end{tabular}

\section{Case Studies for The Sea-keeping Performance Assessment}

A methodology to estimate the sea-keeping performance based on the spectral approach was presented in the previous section. According to this methodology, the sea-keeping performances were calculated as a function of the hydrodynamic characteristics of the ship and of the environmental conditions where the ship operates, while the ship responses to irregular sea states were evaluated using both methods based on standard spectral techniques and probabilistic.

Taking into account the methodology mentioned, the computations related to two containerships that usually operate in the Black Sea basin are performed in this section. The containerships main dimensions and the offset ships lines are presented in Table 2 and Fig. 1 and Table 3 and Fig. 2, respectively.

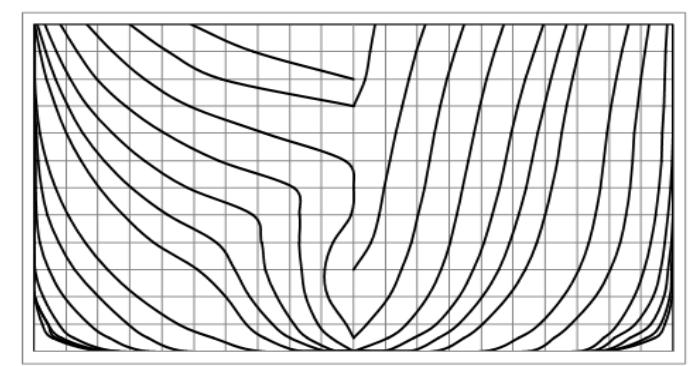

Fig. 1: The offset ship lines of the containership C1

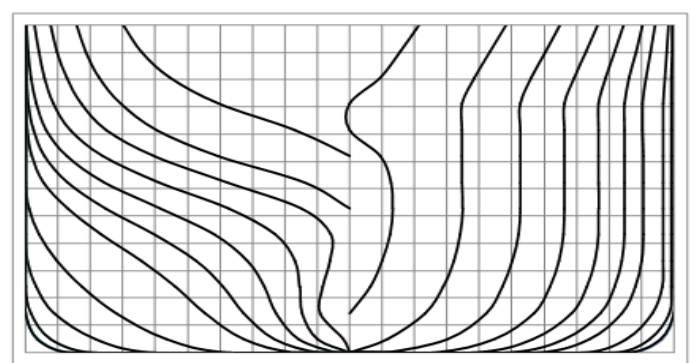

Fig. 2: The offset ship lines of the containership C2 
Table 2: The main dimensions of the containership C1

\begin{tabular}{|l|r|}
\hline \multicolumn{1}{|c|}{ Containership } & \multicolumn{1}{c|}{ C1 } \\
\hline Length overall & 139.965 \\
\hline Length between perp., Lpp $(\mathrm{m})$ & 130.00 \\
\hline Beam, $B(\mathrm{~m})$ & 21.80 \\
\hline Draft, $T(\mathrm{~m})$ & 7.335 \\
\hline Depth, $D(\mathrm{~m})$ & 9.50 \\
\hline Displacement, $\Delta$ (ton) & 17974.50 \\
\hline Long. position of CG, $(\mathrm{m})$ & -2.526 \\
\hline Vertical position of CG, $(\mathrm{m})$ & 6.30 \\
\hline Service speed, $V_{s}(\mathrm{kts})$ & 1.00 \\
\hline $\begin{array}{l}\text { Transversal metacentric height, GMt } \\
(\mathrm{m})\end{array}$ & 2.618 \\
\hline
\end{tabular}

Table 3: The main dimensions of the containership C2

\begin{tabular}{|l|r|}
\hline \multicolumn{1}{|c|}{ Containership } & \multicolumn{1}{c|}{ C2 } \\
\hline Length overall & 149.50 \\
\hline Length between perp., Lpp $(\mathrm{m})$ & 140.00 \\
\hline Beam, $B(\mathrm{~m})$ & 23.60 \\
\hline Draft, $T(\mathrm{~m})$ & 7.29 \\
\hline Depth, $D(\mathrm{~m})$ & 13.50 \\
\hline Displacement, $\Delta$ (ton) & 18000.00 \\
\hline Long. position of CG, (m) & 71.73 \\
\hline Vertical position of CG, $(\mathrm{m})$ & 8.30 \\
\hline Service speed, $V_{s}(\mathrm{kts})$ & 20.00 \\
\hline $\begin{array}{l}\text { Transversal metacentric height, GMt } \\
(\mathrm{m})\end{array}$ & 2.02 \\
\hline
\end{tabular}

The first step is to calculate the relevant ship response transfer functions for all directions between the head waves and the following waves, where $180^{\circ}$ stands for the head waves. The transfer functions define the amplitude of the response due to a unit wave excitation and they are computed for all the directions considered between the heading and the following waves. These types of results are illustrated in Fig. 3 for both containerships considered. The graphs present the transfer functions of roll, pitch and heave, for seven headings.

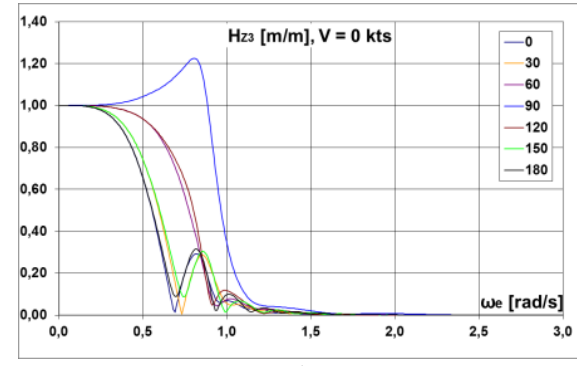

a)

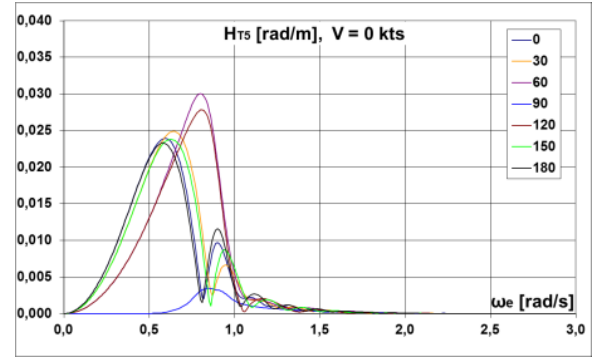

c)

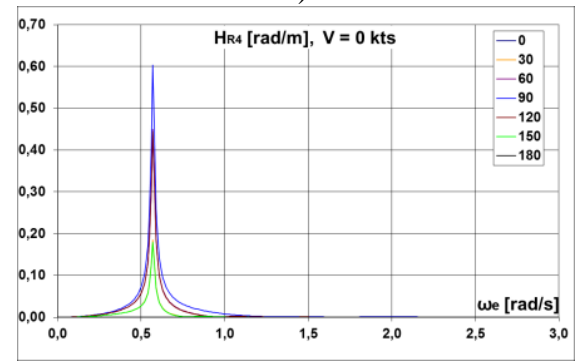

e)

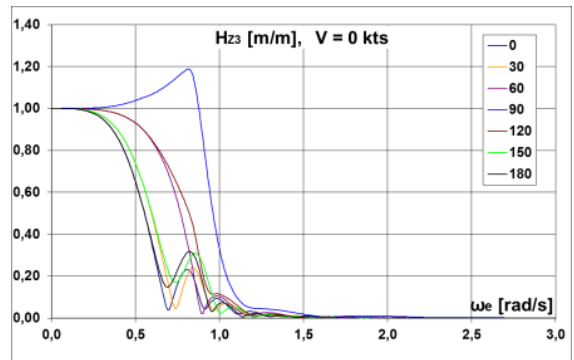

b)

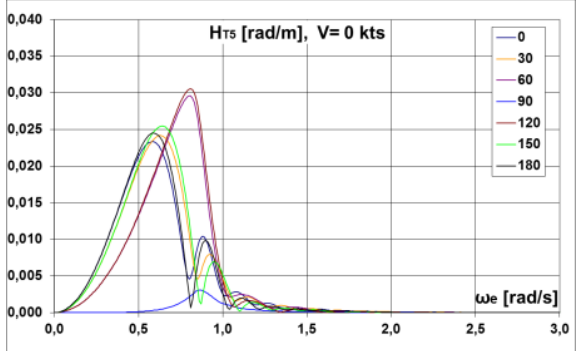

d)

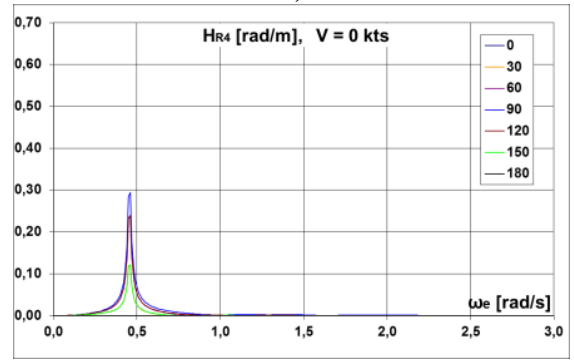

f)

Fig. 3: The transfer functions of the two containerships ( $\mathrm{C} 1$ - left panels, $\mathrm{C} 2$ - right panels) at the service speed computed for: (a, b) Heave $H_{Z Z}[\mathrm{~m} / \mathrm{m}]$, (c, d) Pitch $H_{T 5}[\mathrm{rad} / \mathrm{m}]$, (e, f) Roll $H_{R 4}[\mathrm{rad} / \mathrm{m}]$.

In Fig. $3 \omega_{e}(\mathrm{rad} / \mathrm{s})$ represents the encounter frequency calculated as follows: 


$$
\omega_{e}=\omega_{0}-\frac{\omega_{0}^{2}}{g} \cdot V \cdot \cos (\beta),
$$

where $\omega_{0}$ is the wave frequency, $V$ is the ship speed and $\beta$ is the heading wave.

For positions selected on the ship, the transfer functions, which include the absolute ships motions and some derived responses, such as relative motions and vertical and lateral accelerations, were computed. The coordinates of these points are presented in Table 1. Their positions are related to a reference system fixed with respect to the mean section of the ship. The axis is oriented in the vertical upward direction passing through the center of gravity of the ship, while the $x-y$ plane coincides with the undisturbed free surface of the water. The $x$ axis is along the longitudinal direction of the ship and is pointing to the bow, while the $y$ axis is pointing to the port direction. Only a separation between headings of 30 degrees was considered, resulting in seven headings.

The limiting significant wave heights have been determined as a function of a range of mean wave periods, based on the above mentioned criteria. The sea-keeping criteria appear as limiting curves with the limiting significant wave height as the ordinate and with the wave period along the abscissa. The vessel meets the seakeeping criteria for the combinations wave height-period below (all) the boundary curves. Such graphs give information about which significant wave height is critical for the different criteria, and which criterion is the limiting one at different wave periods and headings.

There are combinations of the wave heights and the wave periods that cannot exist because the waves would be too steep to be stable, and they break. The breaking wave height $H_{s}^{b r}$ was found by Myrhaug and Dahl (1996) as a function of the peak period $T p$ :

$$
H_{s}^{b r}\left(T_{p}\right)=0.105 T_{p}^{2}
$$

where $T_{p}=1.287 T_{z}$ for a JONSWAP wave spectra (Hasselmann et al., 1973).

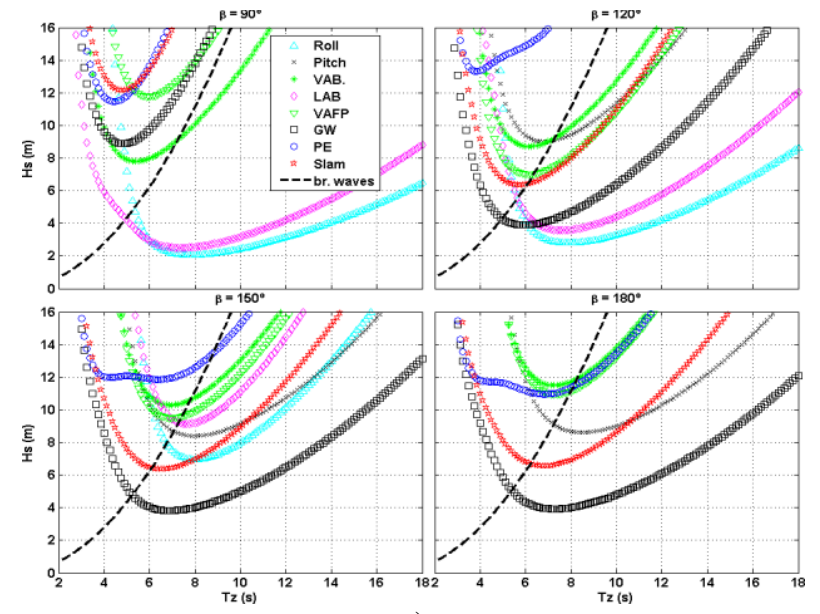

a)

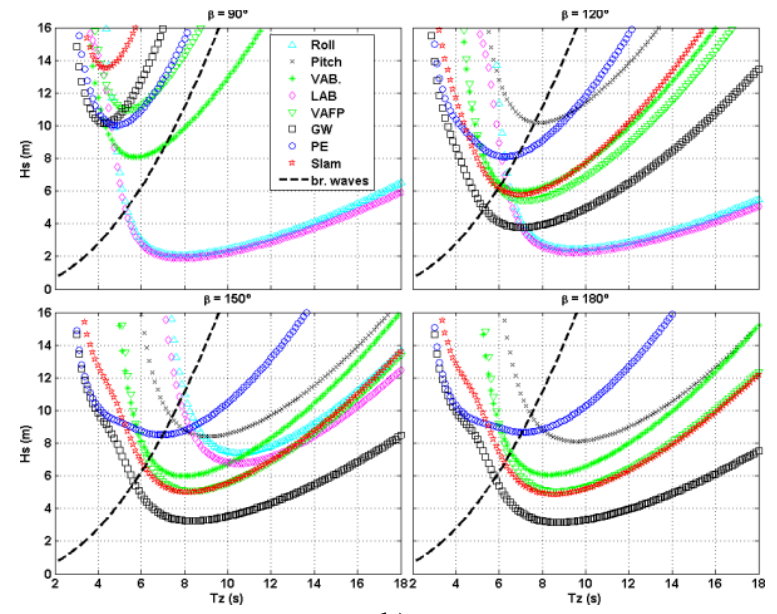

b)

Fig. 4: Maximum allowed significant wave heights for all criteria, containership C1 at 0kts (a) and 18kts (b) speed and various headings $\left(120^{\circ}\right.$ and $90^{\circ}$ - upper panels; $180^{\circ}$ and $150^{\circ}$ - bottom panels)

Figs. 4 and 5 present the results obtained for the two vessels considered and which are operating with the speeds of $0 \mathrm{kts}$ (no advance) and the service speeds of $18 \mathrm{kts}$ and $20 \mathrm{kts}$, respectively. The results are presented only for the heading angles between $90^{\circ}$ and $180^{\circ}$. The theoretical limit for the breaking waves is plotted together with the operability boundary limits (the black dashed line). The graphs show clearly which are the responses that limit most the ship operability, and for which headings.

From Fig. 4, it can be observed that for both speeds, GW appears to be the criterion which limits the operability of the containership $\mathrm{C} 1$ for heading angles of $180^{\circ}$ and $150^{\circ}$, while for heading angles of $120^{\circ}$ and $90^{\circ}$ the limiting criterion at $0 \mathrm{kts}$ is roll, and at $18 \mathrm{kts}$ is LAB. With the increase of the velocity, the limiting curves of the maximum significant wave height decrease drastically for VAB and VAFP corresponding to heading angles between $180^{\circ}$ to $120^{\circ}$, while for Slam only a slight decrease appears. 


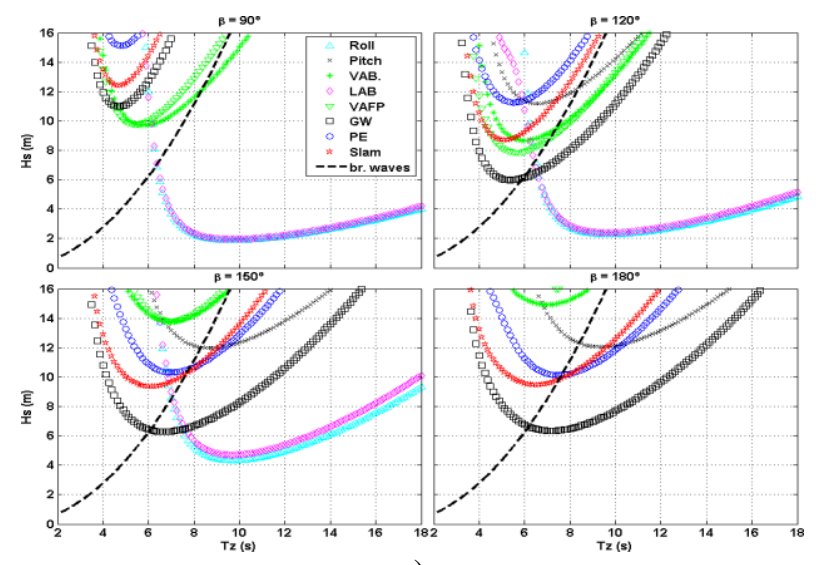

a)

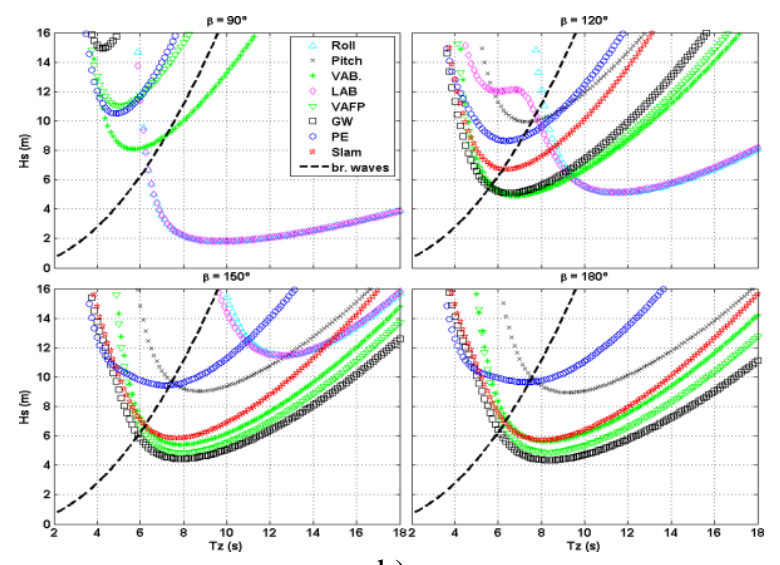

b)

Fig. 5: Maximum allowed significant wave heights for all criteria, containership C2 at 0kts (a) and 20kts (b) speed and various headings $\left(120^{\circ}\right.$ and $90^{\circ}$ - upper panels; $180^{\circ}$ and $150^{\circ}$ - bottom panels)

From Fig. 5 it is observed that at 0kts the limiting criterion for the containership C2 is roll, for heading angles between $90^{\circ}$ to $150^{\circ}$, while for a heading angle of $180^{\circ}$, GW limits the operability of this vessel. The increasing of the ship's speed does not modify very much the maximum significant wave height of the limiting curves for a heading angle of $90^{\circ}$, while for the heading angles between $120^{\circ}$ and $180^{\circ}$ important changes are observed. For a heading angle of $120^{\circ}$ there are various curves that limit the ship operability, function of the mean wave period. For heading angles of $150^{\circ}$ and $180^{\circ}$ it is clear that GW limits the operability of the containership.

\section{Assessment of Vessel's Navigation Operability in The Black Sea}

The target area considered in the present work is the basin of the Black Sea and the information concerning the sea states are delivered by a wave prediction system, SWAN based, that was already implemented and validated against in situ measurements and remotely sensed data (Rusu et al., 2014; Rusu and Butunoiu, 2014). As already mentioned, two containerships were considered, as case studies for assessing the operability of the vessels in the Black Sea basin. The information provided concerning the sea state conditions $\left(H_{s}, T_{z}\right.$ and wave direction) allows a better assessment of the seakeeping performances of the vessels under operational conditions. The significant wave height scalar fields and the wave vectors simulated in the Black Sea basin using the wave prediction system SWAN based are illustrated in Fig. 6 for the high energetic conditions corresponding to three different time frames: 2005/02/04-h06,
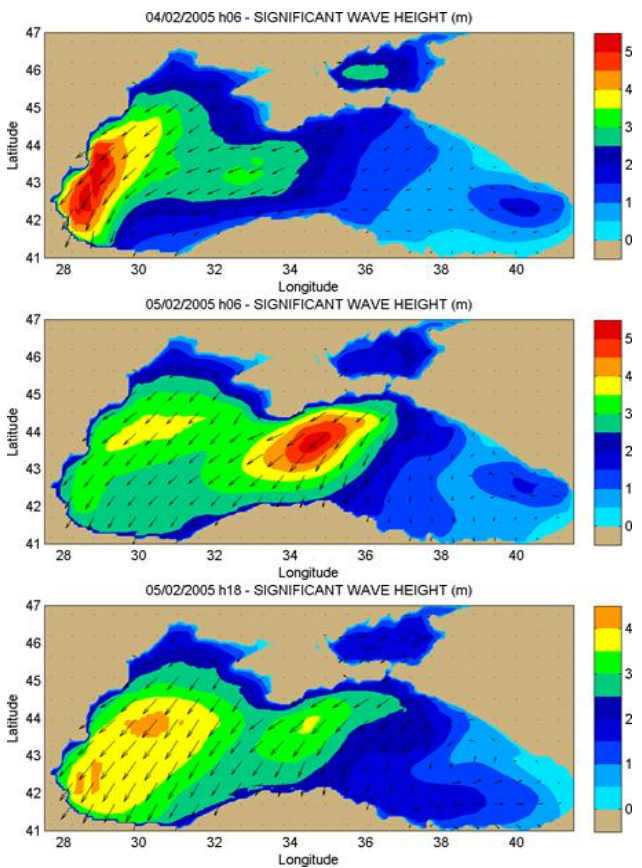

Fig. 6: Significant wave height scalar fields and wave vectors. Results of the simulations with the wave prediction system in the Black Sea basin for the high energetic conditions corresponding to the time frames: 2005/02/04-h06, 2005/02/05-h06 and 2005/02/05-h18 2005/02/05-h06 and 2005/02/05-h18.

Starting from the maximum allowed significant wave height curves (some examples are presented in Figs. 4 and 5) computed for various criteria and function of $T_{z}$, for the sea states characterized by a specific pair of $H_{s}$ and $T_{z}$, corresponding to a point that is inside the green colored area (see Fig. 7) the containership can operate satisfying all operability criteria defined at the ship's speed and for that heading angle. As it can be seen, the significant wave heights that limit the green area (denoted as $H_{\text {slimit }}$ ) are the lowest values of $H_{\text {smax }}$ computed for all the criteria considered. 


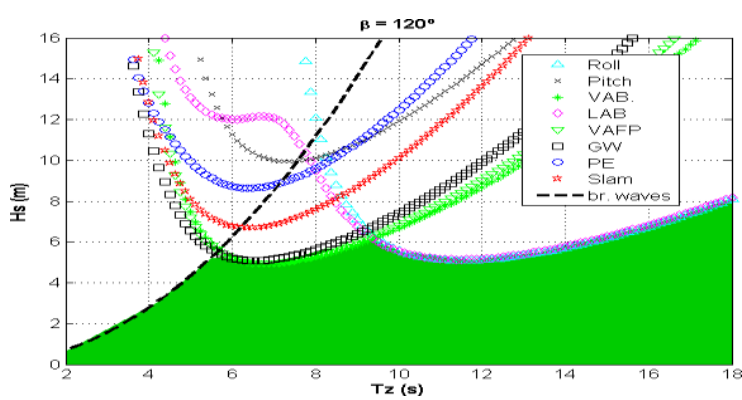

Fig. 7: Maximum significant wave heights for which the containership $\mathrm{C} 2$ can operate satisfying all the operability criteria, for the heading $120^{\circ}$ and the service speed ( $\left.\mathrm{Vs}=20 \mathrm{kts}\right)$
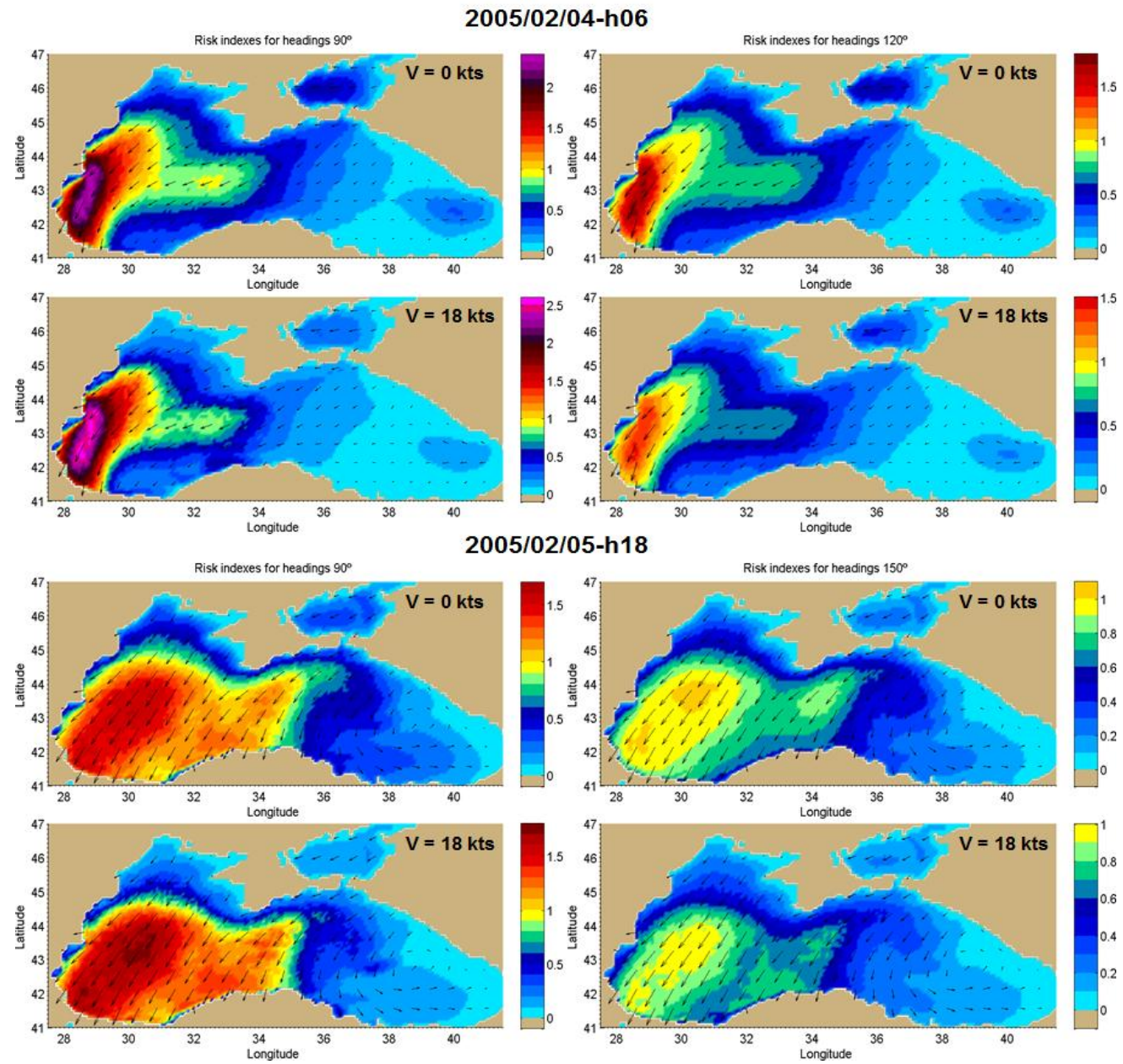

Fig. 8: Maps of the operational risk indexes computed for all criteria and various heading waves, considering that the containership $\mathrm{C} 1$ operates in the Black Sea with the speeds of 0kts (upper panels for each case) and 18kts (bottom panels for each case), the time frames considered are: 2005/02/04-h06 and 2005/02/05-h18

In Fig. 8 several maps of the risk indexes are presented, as computed for the containership $\mathrm{C} 1$, and corresponding to two different ship speed conditions (0kts and 18kts) and various heading waves. These risk indexes correspond for two wave conditions (2005/02/04-h06 and 2005/02/05-h18) presented in Fig. 6, where it can be noticed that in the first case $H_{s}$ fields with values greater that $5 \mathrm{~m}$ can be encountered in the western side of the sea.

For the conditions corresponding to the time frame 2005/02/04-h06, if the ship C1 is motionless in the western side of the basin with heading angles of $90^{\circ}, R I$ has elevated values (greater than 2). Once the velocity is 
enhanced, but keeping the some heading, it can be noticed that in the western side of the sea a zone occurs in which indexes exceed even values of 2.5 . This feature indicates the necessity of modifying the heading angle. It can be noticed that for heading angle of $120^{\circ}$ the $R I$ values are decreasing (although they are still greater than 1 ), but by increasing the ship velocity the values of these risk indexes decay.

Also in the second case considered, corresponding to the time frame 2005/02/05-h18, the risk indexes, computed in the western side of the Black Sea for heading angles of $90^{\circ}$, have values greater than 1 for an extended area. The modification of the ship direction, so that the heading angles to have values of about $150^{\circ}$, makes the values of the risk indexes to become lower than 1 and thus no limiting criterion is exceeded.
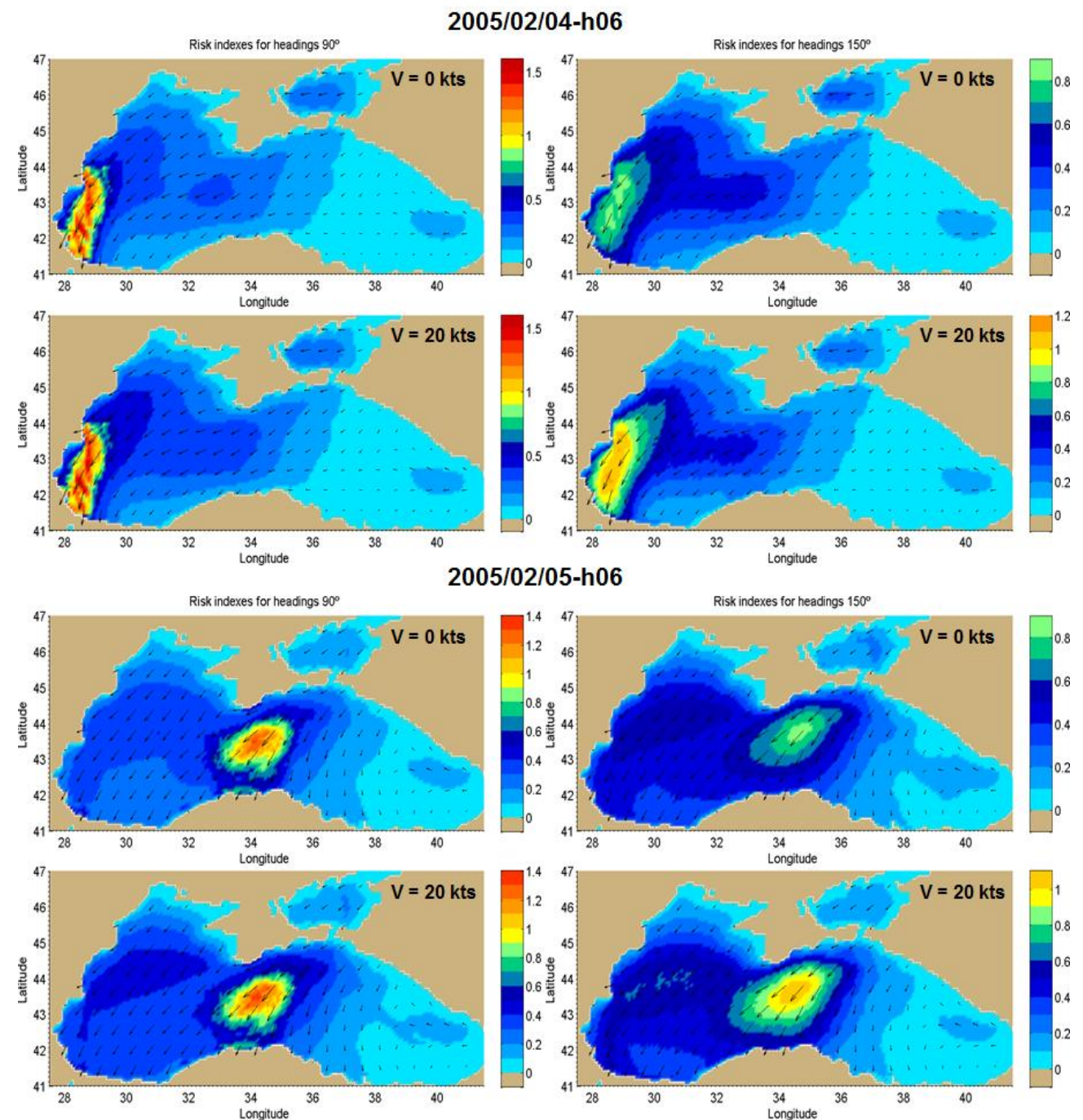

Fig. 9: Maps of the operational risk indexes computed for all criteria and various heading waves, considering that the containership C2 operates in the Black Sea with the speeds of 0 kts (upper panels for each case) and 20kts (bottom panels for each case), the time frames considered are: 2005/02/04-h06 and 2005/02/05-h06

Fig. 9 presents the maps of the risk indexes computed for the containership $\mathrm{C} 2$ for two different ship speed conditions (0kts and 20kts) and heading angles of $90^{\circ}$ and $150^{\circ}$. In this case the risk indexes computed correspond for the first two wave conditions presented in Fig. 6, where energetic conditions with $H_{s}$ greater that $5 \mathrm{~m}$ can be encountered first in the western side of the sea basin, while in the second case, such conditions can be encountered in the central part of the sea.

As in the case of the containership $\mathrm{C} 1$, the operability risk indexes computed for the sea state conditions corresponding to the time frame 2005/02/04-h06 have values greater than 1 in the western zone of the sea for heading angles of $90^{\circ}$ (independent of the ship velocity). For the case when the velocity is 0kts, the modification 
of the heading angle from $90^{\circ}$ to $150^{\circ}$ reduces significantly the risk indexes and practically no zone with risk indexes greater than 1 is encountered. On the other hand, for the case when the ship velocity is $20 \mathrm{kts}$, only a small reduction of the indexes is noticed, and some small zones with values of the risk indexes between $1.1 \div 1.2$ still occur. For the conditions corresponding to the time frame 2005/02/05-h06, the same features in relationship with the behavior of the operability risk indexes can be noticed.

As it was previously noticed, besides the criterion considered, the ship speeds and headings have a great influence on the maximum values allowed for the significant wave height. On the other hand, the knowledge in detail of the encounter angle between the waves and the ship is rather limited, and for this reason some approximations are required. That is why, in the following computations the operability indexes related to each criterion are estimated first considering that $H_{s c \max }$ is the average value of the maximum allowed significant wave height for all the seven headings considered in the seakeeping code, and then for circular sectors of $60^{\circ}$. Using the average value of the maximum allowed significant wave height for a criterion $\left(H_{s c \max }\right)$ corresponding to heading angles of $180^{\circ}, 150^{\circ}$ and $120^{\circ}$, the indexes for headings in the sector $180 \div 120^{\circ}$ are estimated. Other two sectors are defined for the intervals $120^{\circ} \div 60^{\circ}$ and $60^{\circ} \div 0^{\circ}$.
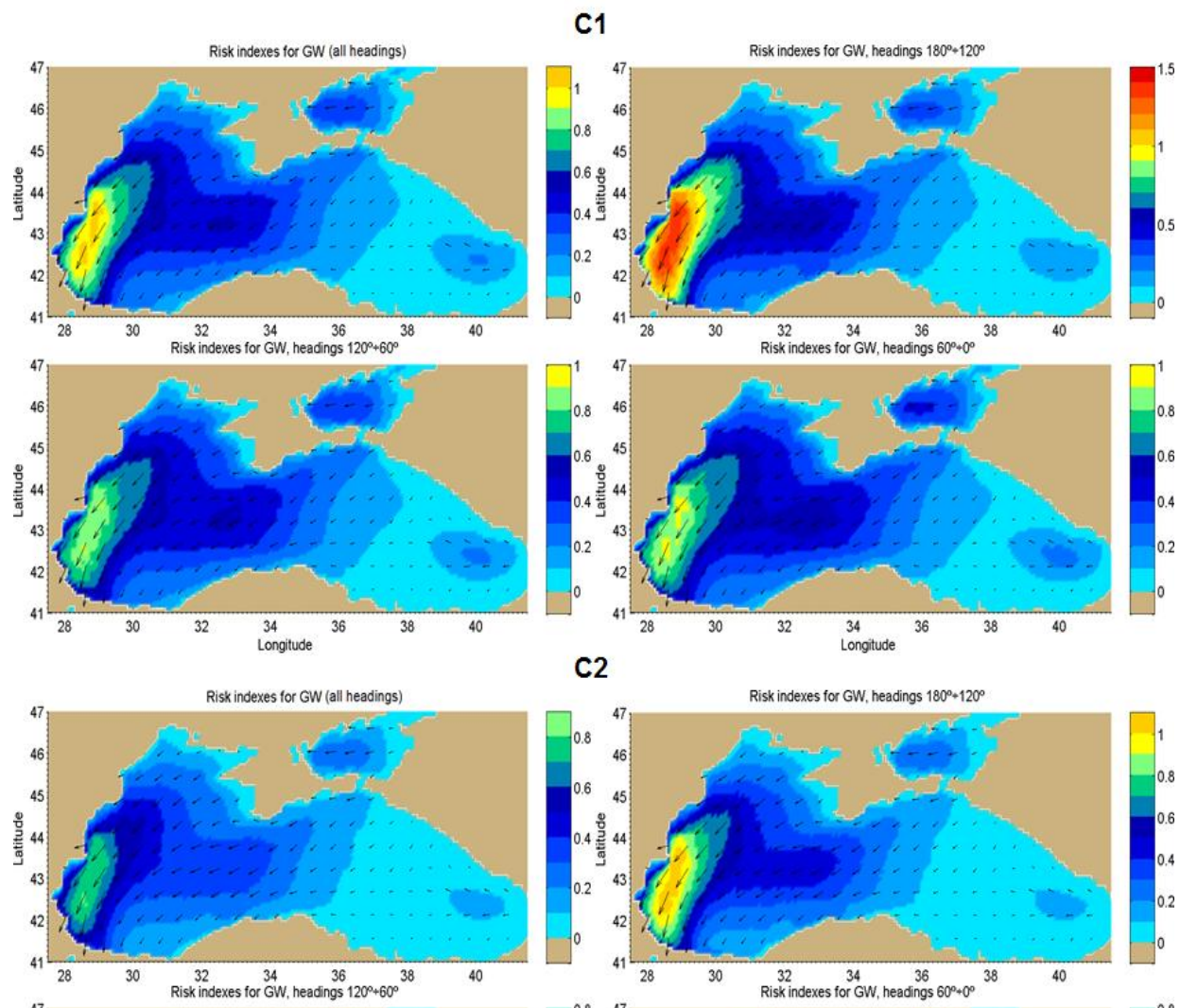

\section{C2}
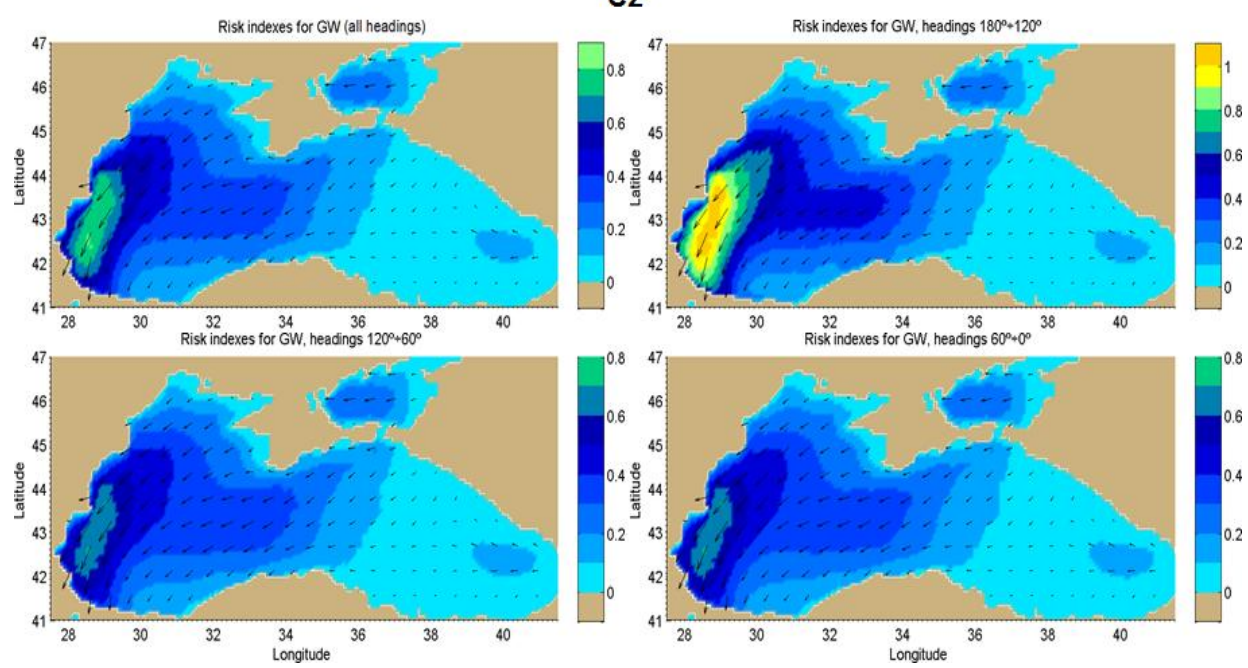

Fig. 10: Maps of the operational risk indexes computed for the $\mathrm{GW}$ criterion, considering that $\mathrm{C} 1$ and $\mathrm{C} 2$ operate in the Black Sea basin with the service speeds, for all headings and considering circular sectors for the heading waves, time frame 2005/02/04-h06 
Fig. 10 indicates that the values of the indexes computed for GW present significant variations in relationship with the sector considered for the wave headings for the two containerships that operate at the service speed. As expected, the operability of both ships is limited in a certain degree by GW for heading waves in the sector $180^{\circ} \div 120^{\circ}$. If in the case of the containership $\mathrm{C} 2$, the operability indexes reach values equal to 1 only for $H_{s}$ $>5 \mathrm{~m}$, in the case of $\mathrm{C} 1$, the operability indexes have values greater than 1 on extended areas (having values even of about 1.5). It results that in order not to be affected by GW, a change in the ship direction of advance is required for the navigation of the containership $\mathrm{C} 1$, such as the heading angles to be situated in another sector.

The same computation approach was applied for $\mathrm{C} 1$ at the service speed, the criterion analyzed this time being roll with heading angles in the three sectors previously considered. The results are presented in Fig. 11 for the sea states corresponding to the time frame 2005/02/05-h06. The maps show clearly that the headings from the sector $120^{\circ} \div 60^{\circ}$ are those that limit the ship operability in the center of the Black Sea basin. Thus, if in its mission the ship C1 should navigate with the service speed in the center of the Black Sea basin considering the environmental conditions corresponding to the time frame 2005/02/05-h06 on a route linking the east side of the basin with the west side, then the heading angles would be exactly in the sector $120^{\circ} \div 60^{\circ}$. According to the results presented in Fig. 11, for the ship to navigate safety, either the route should be modified, such as the ship to pass through areas with operability indexes for roll smaller than 1, or alternatively to change the navigation direction such as the heading
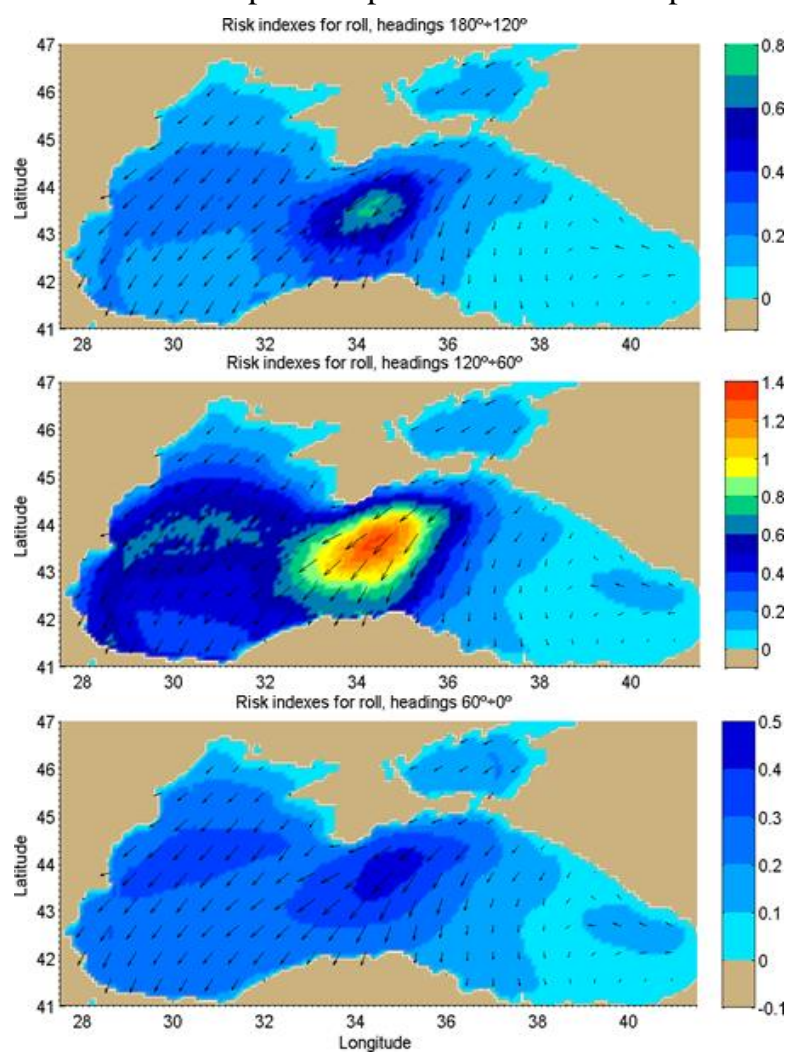

Fig. 11: Maps of the operational risk indexes computed for the roll criterion, considering that $\mathrm{C} 1$ operates in the Black Sea basin with the service speed, for circular sectors of the heading waves, time frame 2005/02/05-h06 angles to be in other sectors.

\section{Conclusions}

Reducing the navigation risks become in the last decades a problem with worldwide increasing importance. This is mainly because the economic activities are in a continuous enhancement in both offshore and nearshore areas inducing a relevant increase of the navigation traffic. On the other hand, the target area of the study performed herewith is the basin of the Black Sea, environment that might be considered as presented elevated risks for both deep sea and coastal navigation.

In this context, the present work describes an effective methodology that allows the assessment of the ships operability in the Black Sea. The examples presented are related to two containerships with different dimensional characteristics, but having the same displacement. The information provided by the application developed can be useful for the ships crews to plan better the safety operations of their ships and to identify proper the areas in which the level of operability of the ship will be restricted due to weather conditions.

In order to check the robustness of the methodology developed in this work, various criteria for the analysis of the results were considered. Nevertheless, it resulted that the changes of the criteria did not lead in general to significant changes concerning the most dangerous zones relatively to the sea states corresponding to a certain time frame. From the case studies presented in the previous section it could be noticed that changes of the ship direction or of the ship speed make the values of indexes to decrease, and thus no limiting criterion is exceeded. Nevertheless, this is not always enough and sometimes it is really necessary to modify both direction and speed, so that the values of the risk indexes to be reduced (see for example the case of the ship $\mathrm{C} 1$ for the conditions 
corresponding to the time frame 2005/02/04-h06). It was also noticed that, from the maps of the operational risk indexes, the dangerous areas in relationship with the safety of both containerships could be easily identified as also the differences that occur due the constructive characteristics between the two ships considered.

It has to be also highlighted that the present study was carried out only for containerships and it was related to the wave conditions characteristic to the basin of the Black Sea. Nevertheless, the approach proposed in this work can be easily extended to any type of ship operating in any environment (see Rusu and Guedes Soares, $2014 a, b)$ where reliable information about the sea states (significant wave highs and periods) is available.

\section{Acknowledgment}

This work was supported by a grant of the Romanian Ministry of National Education, CNCS - UEFISCDI PNII-ID-PCE-2012-4-0089 (project DAMWAVE).

\section{References}

Antão, P., Almeida, T., Jacinto, C. and Guedes Soares, C. (2008): Causes of Occupational Accidents in the Fishing Sector in Portugal, Safety Science, Vol. 46, Issue 6, pp. 885-899. http://dx.doi.org/10.1016/j.ssci.2007.11.007

Antão, P., Grande, O., Trucco, P. and Guedes Soares, C. (2008): Analysis of maritime accident data with BBN modelling, Safety, Reliability and Risk Analysis - Theory, Methods and Applications, Martorell, S., Guedes Soares, C. \& Barnett, J. (Eds), Balkema, Taylor \& Francis Group, Vol. II, pp. 3265-3274.

Bertram, V., Veelo, B., Söding, H. and Graf, K. (2006): Development of a freely available strip method for Seakeeping, Proc. $5^{\text {th }}$ International Conference on Computer Aplications and Information Technology in the Maritime Industries, 8-10 May 2006, Oegstgeest, The Netherlands, pp. 356-369.

Bitner-Gregersen, E.M. and Guedes Soares, C. (2007): Uncertainty of Average Wave Steepness Prediction from Global Wave Databases, Advancements in Marine Structures, C. Guedes Soares and P. K. Das (Eds.), London UK, pp. 3-10.

Booij, N., Ris, R.C. and Holthuijsen, L.H. (1999): A third-generation wave model for coastal regions, Part I, Model description and validation, Journal of Geophysical Research: Oceans, Vol. 104, Issue C4, pp. 7649-7666. http://dx.doi.org/10.1029/98JC02622

Domnişoru L. (2001): Ship's Dynamics, Ocilations and vibrations of the ship hull, Technical Publishing House, Buchares, Romania (in Romanian).

Domnişoru, L., Rubanenco, I. and Mirciu, I. (2009): DYN programs package (modules DYN_OSC, DYN_LIN, DYN_NLN.), software for the ship dynamics analysis, Faculty of Naval Architecture, Dunarea de Jos Galati University, Romania.

Eleye-Datubo, A.G., Wall, A., Saajedi, A. and Wang, J. (2006): Enabling a Powerful Marine and Offshore Decision-Support Solution through Bayesian Network Technique, Risk Analysis, Vol. 26, Issue 3, pp. 695-721. http://dx.doi.org/10.1111/j.1539-6924.2006.00775.x

Fonseca, N. and Guedes Soares, C. (2002): Sensitivity of the expected ships availability to different seakeeping criteria, Proc. $21^{\text {th }}$ International Conference on Offshore Mechanics and Arctic Engineering (OMAE2002), ASME, paper OMAE-28542.

Gasparotti, C. (2010): Risk assessment of marine oil spills, Environmental Engineering and Management Journal, Vol. 9, No. 4, pp. 527-534.

Guedes Soares, C., Bitner-Gregersen, E.M. and Antão, P. (2001): Analysis of the frequency of ship accidents under severe North Atlantic weather conditions, Proc. of The Royal Institution of Naval Architects (RINA), Design and Operation for Abnormal Conditions II, pp. 221-230.

Hanzu-Pazara, R. (2007): Risk assessment in marine industry, The human errors and the impact on the environment, Nautical Press, Constanţa, pp. 43-46 (in Romanian).

Hasselmann K., Barnett, T.P., Bouws, E., Carlson, H., Cartwright, D.E., Enke, K., Ewing, J.A., Gienapp, H., Hasselmann, D.E., Kruseman, P., Meerburg, A., Müller, P., Olbers, D.J., Richter, K., Sell, W. and Walden, H. (1973): Measurements of Wind-Wave Growth and Swell Decay During the Joing North Sea Wave Project (JONSWAP), Deutsche Hydrograph. Zeit., Erganzungsheft Reihe 12, A8.

IMO (1994): International Safety Management IMO code, issued by International Management Organization, 739 (18), London. 
ITTC (1999): Recommended Procedures and Guidelines, Testing and Extrapolation Methods, High Speed Marine Vehicles, Excerpt of ISO 2631, Seasickness and Fatigue, report 7.5-02-05-04.1.

Milan I. and Gomoiu M. (2008): Causes and consequences of oil marine pollution, Geo-Eco-Marine Review 14 - Supplement no. 1, Earth Sciences, Knowledge and Environment, pp. 14-22.

Myrhaug, D. and Dahl, E.A. (1996): Ship capsize in breaking waves, Fluid Structure Interaction in Offshore Engineering, S. K. Chakrabarti, Ed., Computational Mech. Publications, Chap. 2, pp. 146-164, Advances in Fluid Mechanics, M. Rahman, Series Editor.

Norrington, L., Quigley, J., Russell, A. and Van der Meer, R. (2008): Modelling the reliability of search and rescue operations with Bayesian Belief Networks, Reliability Engineering \& System Safety, Vol. 93, Issue 7, pp. 940-949. http://dx.doi.org/10.1016/j.ress.2007.03.006

Platonov, G.V. and Trub, S.M. (2010): Improvement of Seakeeping Qualities of Small Fishing Vessels as One of the Ways to Increase Their Energy Efficiency, First International Symposium on Fishing Vessel Energy Efficiency E-Fishing, Vigo, Spain.

Rusu, E., Soares, C.V. and Rusu, L. (2005): Computational Strategies and Visualization Techniques for the Waves Modeling in the Portuguese Nearshore, Maritime Transportation and Exploitation of Ocean and Coastal Resources, Editors Taylor \& Francis, London, Vol II, pp. 1129-1136.

Rusu, E. (2010a): Modeling of wave-current interactions at the Danube's mouths, Journal of Marine Science and Technology, Vol. 15, Issue 2, pp. 143-159. http://dx.doi.org/10.1007/s00773-009-0078-x

Rusu, E. (2011): Strategies in using numerical wave models in ocean/coastal applications, Journal of Marine Science and Technology- Taiwan, Vol. 19, No. 1, 58-73.

Rusu, L. (2010b): Application of numerical models to evaluate oil spills propagation in the coastal environment of the Black Sea, Journal of Environmental Engineering and Landscape Management, Vol. 18, No. 4, pp. 288295.

Rusu, L. and Ivan, A. (2010): Modelling Wind Waves in the Romanian Coastal Environment, Environmental Engineering and Management Journal, Vol. 9, No. 4, pp. 547-552.

Rusu, L. and Guedes Soares, C. (2013): Evaluation of a high-resolution wave forecasting system for the approaches to ports, Ocean Engineering, Vol. 58, pp. 224-238. http://dx.doi.org/10.1016/j.oceaneng.2012.11.008

Rusu, L. and Butunoiu, D. (2014): Evaluation of the wind influence in modeling the Black Sea wave conditions, Environmental Engineering and Management Journal, Vol. 13, No. 2, pp. 305-314.

Rusu, L. and Guedes Soares, C. (2014a): Forecasting containership responses in the Azores Archipelago, Developments in Maritime Transportation and Exploitation of Sea Resources - Guedes Soares \& López Peña (eds), Taylor \& Francis Group, London, Vol 2, pp. 987-993.

Rusu, L. and Guedes Soares, C. (2014b): Forecasting fishing vessel responses in coastal areas, Journal of Marine Science and Technology, Vol. 19, Issue 2, pp. 215-227. http://dx.doi.org/10.1007/s00773-013-0241-2

Rusu, L., Bernardino, M. and Guedes Soares, C. (2014): Wind and wave modelling in the Black Sea, Journal of Operational Oceanography, Vol. 7, No. 1, pp. 5-20.

Salvesen, N., Tuck, E.O. and Faltisen, O. (1970): Ship motions and sea loads, Transactions Society Naval Architects Marine Engineers, Vol. 78, pp. 250-287.

Sariöz, K. and Narli, E. (2005): Effect of criteria on seakeeping performance assessment, Ocean Engineering 32, Issue 10, pp. 1161-1173. http://dx.doi.org/10.1016/j.oceaneng.2004.12.006

Toffoli, A., Lefevre, J.M., Monbaliu, J., Savina, H. and Bitner-Grgersen, E. (2003): Freak waves: clues for prediction in ship accidents, Proc. 13th International Offshore and Polar Engineering Conference, Honolulu, Hawaii, USA, 25-30 May 2003, pp. 23-29.

Trucco, P., Cagno, E., Grande, O. and Ruggeri, F. (2006): A Bayesian Approach for Integrating Organizational Factors in Risk Analysis, Safety and Reliability for Managing Risk, C., Guedes Soares \& E. Zio (Eds.), Balkema, Taylor \& Francis Group, Vol. I, pp. 443-450.

Zhang, S., Sun, X., Zhang, S. and Chen, X. (2006): Risk analysis methods in oil spill contingency plans, Proc. $7^{\text {th }}$ Annual General Assembly of the International Association of Maritime University, Dalian Maritime University, pp. 34-41.

Wayment, E.C. and Wagstaff, B. (1999): Appropriate technology for oil spill management in developing nations, Pure and Applied Chemistry, Vol. 71, Issue 1, pp. 203-208. http://dx.doi.org/10.1351/pac199971010203 